\title{
A SELF-CLOSING WATER BUCKET FOR PLANKTON INVESTIGATIONS \\ BY
}

\section{CHARLES ATWOOD KOFOID}

The securing of samples of water of considerable volume from known levels for filtration by other methods than that of the silk net is a prime desideratum in the study of the vertical distribution of marine organisms. The drawn net method is available and in a measure adequate for the larger organisms such as the tunicates, mollusks, crustaceans and coelenterates, though it fails in the case of the eggs and young of some species. When finer grades of silks are used, such for example as Nos. 12-20, the error due to progressive clogging of the net is greater and increases rapidly with the length of the haul. For quantitative investigations of the more minute organisms the drawn silk net is therefore not to be recommended because of the errors due not only to these results of progressive clogging but also to leakage. The conclusions ('97 a) which I reached regarding the importance of this last named source of error in the case of the fresh water plankton have since been verified for the marine plankton by LoHmann ('02). Other methods of filtration or precipitation must therefore be used in quantitative investigations on the smaller organisms of the plankton.

There are two kinds of apparatus available for securing water for the finer methods of filtration viz. - the plankton pump (Koroid '97) and the water bucket. The pump has been successfully used in marine work by LoHManN ('02) and we have also installed it in our equipment at San Diego. The range of its usefulness is, however, limited by the fact that the expense of installation, and difficulty in handling the hose increases greatly with the depth. We have used the pumping method in depths of 100 fathoms and LoHManN at Syracuse employed it in depths of $110 \mathrm{~m}$. Equipment for greater depths requires considerable modification in the apparatus needed for the support and manipulation of the hose, and, moreover, the time required for work in depths even of 100 fathoms is considerable. The water bucket method on the other hand can be used in any 
depth without other equipment than the dredging engine and cable, and, it is only necessary to increase the capacity of the bucket to obtain a quantity of water sufficient for the purposes of filtration. This method is also preferable because of the ease and rapidity of operation and the permanance of the apparatus. These considerations led to the adoption of the water bucket method in the study of the vertical distribution of the plankton at the San Diego Station.

An examination of existing types of water cups and buckets failed to reveal any one that could be utilized as constructed, for our purposes. Either they were too small and could not easily be enlarged to the required capacity or they were subject to uncertainty in the matter of time or level at which closure was effected, as in all cups operated by the action of propellers, or the closure was not of sufficient certainty and rigidity to insure accuracy when a large quantity of water was handled.

The well-known MEYER's apparatus has a capacity of but one liter and a weight of 15 kilos and is obviously not easily adapted to a considerable increase in capacity. The Sigsber water cup [See TANner ('97)] also has a capacity of but $1 / 2-1$ liter and depends upon the action of a propeller for closure. The Sigsbee cup has been regarded as reliable and accurate in its action by those who have used it, Scнотт ('02), for example, expressing satisfaction with its accuracy. It requires, however, very careful adjustment of the propeller to avoid uncertainty in its closure when the vessel is in a seaway and also needs according to TANNeR ('97) 25-50 fathoms ascent for the operation of the propeller. It is therefore not well adapted for use in the surface strata or in narrow intervals. The KIDDERFlint modification of the Sigsbee cup [See TANner ('97)] is much more complicated in construction without offering any material advantage over the Sigsbee model.

The Ekman [See Ekman and Pettersson ('92)] bottle was designed for use with a rope rather than a dredging cable, and it is furthermore regarded by Pettersson ('94) as uncertain in its closure in depths below $150 \mathrm{~m}$.

The Pettersson ('94 and '98) bottle was designed primarily for temperature work and for obtaining samples for chemical analysis. It consists of three concentric cylinders which drop upon a base and are covered by a lid which is released by propeller action. A device for closing the bucket by messenger PetTersson regards as "a wholly superfluous encumbrance".

On the Valdivia Expedition Sснотт ('02) found difficulty in securing a satisfactory closure of the PeTtensson bucket owing to the leakage between the base and the cylinder and the failure of the rubber stoppers to remain in place. The improvements in the locking device 
and stopper in the PetTersson-Nansen bottle seem to obviate these difficulties [See Mirl ('(0))]. The contents of this bottle are however insufficient for quantitative plankton investigations and the accuracy of a closure by propeller questionable in a large apparatus especially when operated from a relatively small vessel in the heavy seaway prevalent off the coasts of California.

In the modification of this apparatus to the pattern here described I have had the assistance of Mr. Valdemar Arntzen, expert mechanician to the Engineering departments of the University of California, to whom I am indebted for many helpful suggestions, and for aid in planning the details of construction.

This water bucket as finally designed by us is a modification of the Pettersson type, for use with a messenger. It has dimensions over all as follows: height of frame $100 \mathrm{~cm}$.; diameter of frame $25 \mathrm{~cm}$.; capacity 20 liters; weight, empty, about $25 \mathrm{~kg}$. It is constructed of brass throughout, with the exception of the bronze key-faucet, the cast-iron messenger, and steel cable bolt.

It consists of a base ( $b a$. Fig. 1), ribbed beneath for rigidity, four standards (st.) which support the head $(h d$.$) , and enclose the cylinder$ $(c y l$.$) , and lid (l$.$) . Projecting arms (a., a^{\prime}$. and $a^{\prime \prime}$.) from cylinder and lid slide upon two of the standards, and guide these parts into place in closing. The bucket is hung at the end of the dredging cable which is carried through a slot (sl. Fig. 3) to the center of the head where it is secured by a bolt $(p$.). The bucket is operated by messenger which releases the lid from the head and allows it and the cylinder suspended beneath it to drop upon the base.

The base (ba. figs. 1, 2) is a disc-shaped casting $26 \mathrm{~cm}$. in diameter. dished above, with a beveled rim (b. $r$. Fig. 1) which meets a corresponding surface $\left(b^{\prime}, r^{\prime}\right)$ on the drop cylinder. The width of the beveled face is $3 \mathrm{~cm}$. The under surface of the base bears four radiating ribs which terminate in projections which carry the upright standards and are bored to pernit the attachment of a rope buffer for use at sea to prevent injury by striking the sides of the boat. The bottom of the dish is channeled (ch. Fig. 1) towards the edge to an opening into the drain which runs in one of the ribs and opens (o. Fig. 2) beneath one of the standards. This opening contains a slotted plug held in place by a lock nut. The plug is engaged by small lugs on the end of the faucet ( $f$. Fig. 2), inserted in the opening of the drain, which by a rotation of $180^{\circ}$ opens or closes the outlet.

The standards (st. Fig. 1, 2) are brass rods $16 \mathrm{~mm}$. in diameter and $92 \mathrm{~cm}$. long. We used at first heary brass tubing for these standards but they proved to be too lighit for the strains to which they were subjected and they were accordingly filled with brass cores to give the requisite rigidity. Two opposite rods serve as ways for the 
arms (a., $a^{\prime}$., and $a^{\prime \prime}$., Figs. 1, 2) of the sliding cylinder and its lid and bear at the proper place spring catches (sp. c. Figs. 1, 2) which lock the lid securely on the cylinder when the bucket is closed. These

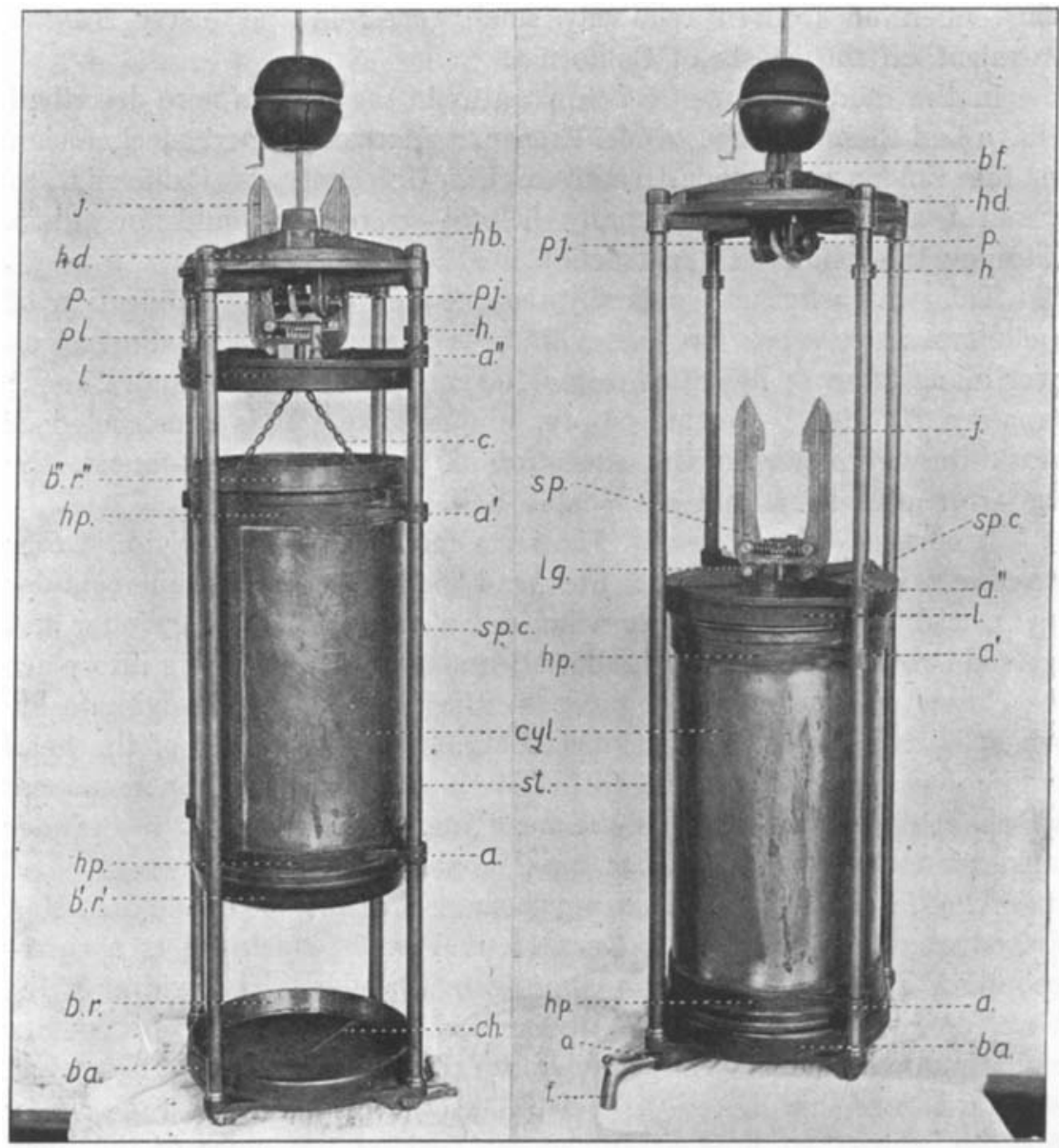

Fig. 1

Fig. 2

Fig. 1. Side view of water bucket set for tripping by inessenger. Key faucet in place: $a ., a^{\prime}$. and $a^{\prime \prime}$. arms of cylinder and lid, $b a$. hase, $b . r . b . r^{*}$, and $b^{\prime \prime} . r$. beveled rims of base, lower and upper ends of cylinder respectively, $c$ brass chain supporting cylinder to lid, $c h$. channel in base leading to drain, cyl. cylinder, $h$. hubs on standards for stopping ascent of lid, $h b$. central hub of head, $h d$. head of frame of bucket, $h p$. hoops on cylinder, $j$. jaws of clutch, $l$. lid, $p$. steel cable pin, $p l$. removable plug, $p j$. projections on under side of head tor cable pin, sp.c.spring catches, st. standards.

Fig. 2. Other side of water bucket after closure by messenger; $b f$. rubber buffer, $f$. key faucet, $l g$. lugs for fastening clutch to lid, $o$. opening of drain containing key faucet, $s p$. springs of clutch. Other abbreviations as in Fig. 1. 
same rods bear near the top hubs ( $h$. Fig. 1, 2) which stop the ascent of the lid so that the springs of the clutch will not be jammed against the top. 'The ends of the standards are securely screwed into the base and locked to the top by nuts.

The cylinder (cyl. Figs. 1, 2) is $47 \mathrm{~cm}$. in height and $23 \mathrm{~cm}$. in diameter, and when closed contains 20 liters. It is made of spring brass brazed at the seam, with hoops ( $h p$. Fig. 1, 2) near the top and bottom from which arms (a. and $a^{\prime}$, Figs. 1, 2) extend laterally. These are bored so as to receive the standards which fit loosely in the openings. The ends of the cylinders are made of ring-shaped castings with beveled faces $\left(b^{\prime} . r^{\prime}\right.$. and $b^{\prime \prime}$. $r^{\prime \prime}$., Fig. 2) which fit respectively into the base and top. A brass chain (c., Fig. 1) fastens the cylinder to the under side of the lid, supporting it at a distance of $10 \mathrm{~cm}$. below the lid and raising it about $20 \mathrm{~cm}$. above the base when the bucket is set for closing. The beveled ends are very carefully fitted by turning in a lathe on common centers and afterwards grinding iu emery so that the joint when the bucket is closed is practically water tight.

The lid (l. Fig. 1, 2) is a disk shaped casting with but one pair of arms ( $a$ "., Figs. 1, 2), bored to receive loosely the standards. The under face is dished and beveled to fit over the top of the cylinder. The upper surface is ribbed for rigidity, and is bored and fitted with a removable plug ( $p l$. Fig. 1) for the insertion of a thermometer in temperature work, or for ingress of air in draining off the contents. Near the center it bears two pairs of lugs (lg. Fig. 2) to which are fastened the jaws of the clutches ( $j$. Figs. 1, 2) which attach the suspended lid and cylinder to the head. The separate jaws of the clutch are L-shaped. the lower arm resting at the end on a central pin in the lid which prevents their movement axially beyond the perpendicular. At the angle the jaws turn on an axis which is set in the lugs on the lid. The jaws are held together by two coiled springs ( $s p$. Fig. 2) placed horizontally near their bases. The tops of the jaws are beveled to receive the descending messenger (Fig. 4) whose impact displaces them laterally so that they release their hold upon the hub ( $h b$. Fig. 1, 3) of the head.

The head (hd. Figs. 1, 2, 3) is a circular casting with a central hub ( $h b$.) four radii and a marginal rim all ribbed for rigidity. Four marginal knob-like projections receive the upper ends of the standards. On the under side are two projections ( $p j$. Figs. 1, 2) which are bored to receive the steel pin ( $p$. Figs. 2,3 ) which passes through the eye at the end of the cable. This steel pin can be slipped to one side sufficiently to admit the cable but cannot be removed or fall out of place. A thong passed through an eye at one end holds it in position when the cable is attached. 
The top of the hub bears a rubber (bf. Fig. 3) held in place by screws. This receives the immediate impact of the descending messenger after the spreading of the jaws of the clutch.

The cable enters the center of the hub and is passed into its central position through a slot (sl. Fig. 3) on the side of the hub which is closed by an arm (a. Fig. 3) hinged at the margin of the head and locked in place by a wing nut which binds a cross bar (c. b. Fig. 3) on the under surface of the radii.

The messenger (Fig. 4) devised by Mr. Arntzen is of a detachable type and is separated into two lateral halves. As shown in the

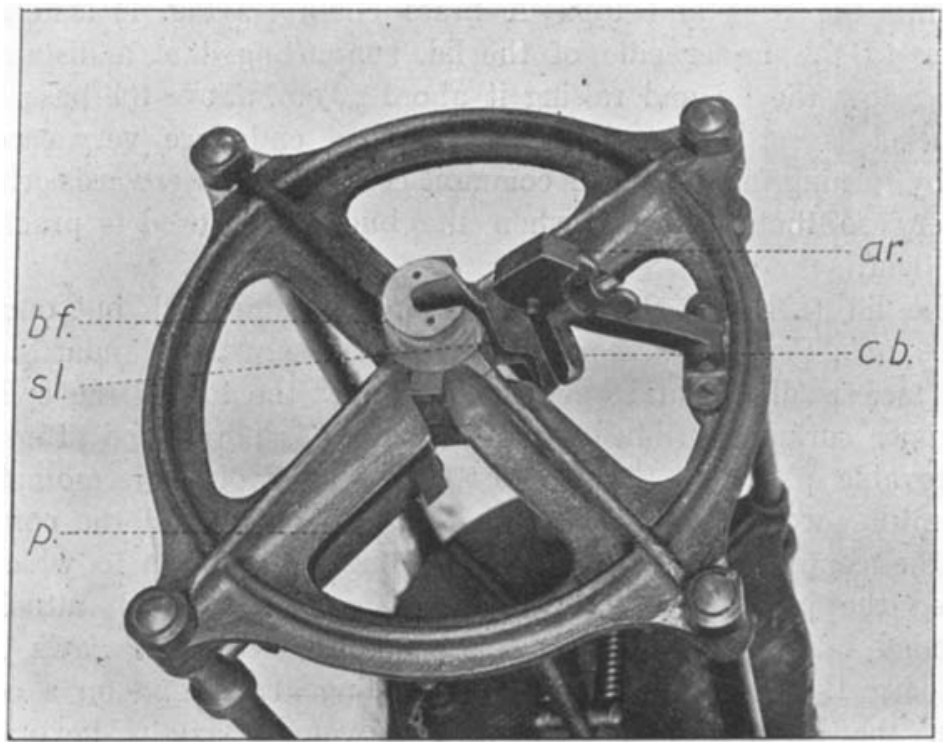

Fig. 3. End view of head of bucket. ar. arm for closing slot in hub. bf. rubber buffer. c. b. cross bar for locking arm in cable slot, sl. slot for cable in central hub. Other abbreviations as in Fig. 1.

median view, the axis of the messenger is channeled out not only for the cable, but at each end for the reception of a divided ring of Babbitt metal which receives the wear in the transit of the messengel over the cable, so that neither messenger nor cable is injured thereby. The Babbitt metal can be easily renewed. A system of channels and blocks on the apposed faces of the messenger prevents the vertical or lateral movement of the parts on each other. The two halves of the messenger are closed over the cable and tied together by a stout piece of marlin. The messenger is thus easily and quickly attached to or removed from the cable.

The operation of the water bucket is a simple procedure. It is 
attached to the eye in the end of the cable $(3 / 8$ in. plow steel wire on the dredging engine of the "Loma", the vessel employed in the work at the San Diego Station) by means of the steel pin. The arm (ar. Fig. 3) is released and lifted from the slot (sl. Fig. 3), the cable passed to the center of the hub ( $h b$. Fig. 5) and the steel pin ( $p$. Fig. 3) is slipped through its eye and secured by a thong. The arm is then replaced and fastened by the wing nut. The lid and suspended cylinder are drawn up to the top, till the jaws take hold of the hub. The beveled faces are then wiped with a cloth into which a little vaseline has been rubbed. The outlet is closed and the faucet removed and the bucket is then ready for the lowering to any desired depth. When the proper amount of cable is reeled out and has come to a

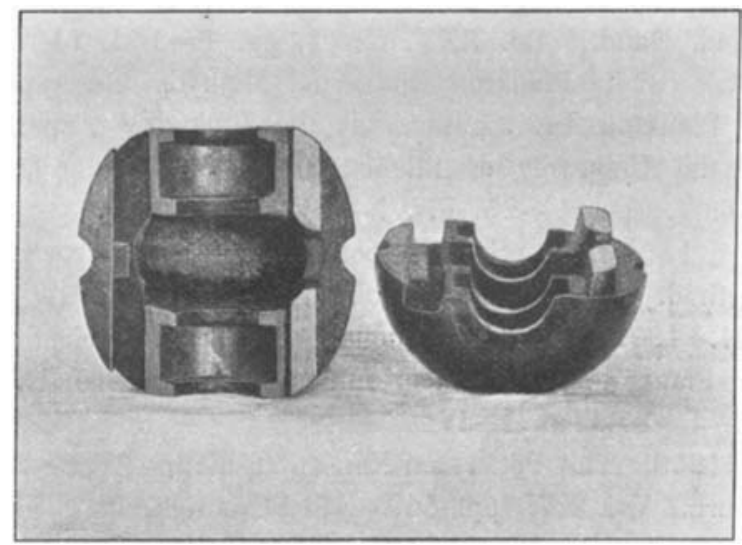

Fig. 4. The Anntzen detachable messenger, sagittal and end views, showing chambers for Babbitt metal, and grooves and blocks which prevent movement of parts on each other.

vertical position the messenger is sent down. The release of the bucket can be detected by the jar on the cable in depths up to about 300 fathoms. The cable is then reeled in and when the bucket is landed on deck the temperature of its contents may be taken by the removal of the plug ( $p$. Fig. 1) and insertion of a thermometer, and the contents drained off by means of the key faucet. In practice it has been found that the closing of the bucket is so secure that it may be rolled about on deck with its load without leakage.

Owing to the volume of the water, temperature tests may be made to depths of 500 fathoms with very slight margin of error. The temperature of the contents of the bucket standing in the open air at $19 \cdot 5^{\circ} \mathrm{C}$. rose from $15.5^{\circ}$ to $15 \cdot 75^{\circ}$ in twenty minutes.

The advantages which this bucket presents are the large volume of water obtained, the certainty of messenger action, the security of 
its closure, and the method of romoving the contents. The bucket was constructed in Mr. AnNTzEn's experimental works at an expense of one hundred dollars.

Berkeley, November 1, 1905

Zoological Laboratory University of California

\section{Bibliography}

Ekman, F. L., och Pettersson, O. 1892. Den svenska hydrografiska expedition ål 1877 under ledning af F. L. Ekman, Kgl. Sv. Vet. Akad. Handl. Bd. XXV, No. 1, pp. 1-163, 14 Taf.

Kofoid, C. A. 1897. Plankton Studies I. Methods and Apparatus in Use in Plankton Investigations at the Biological Experiment Station of the University of Illinois. Bull. Illinois State Lab. Nat. Hist. Vol. V. pp. 1-25, Pls. I-VII.

1897 a. On Some Important Sources of Error in the Plankton Method. Science. N. S. Vol. VI, pp. 829--832.

Lohmann, H. 1902. Neve Untersuchungen über den Reichtum des Meeres an Plankton. Wiss. Meeresuntersuch. Abt. Kiel, N. F. Bd. VII, pp. $1-87$, Taf. $1-1 \mathrm{~V}$.

Mill, H. R. 1900. The Pettersson-Nansen insulating Water-Bottle. Geogr. Journ., Vol. XVI, pp. 469-471, two figs.

Pettersson, 0. 1894. A Review of Swedish Hydrographic Research in the Baltic and North Seas. I. Scott. Geogr. Mag. Vol. X, pp. $281-302,1 \mathrm{Pl}$.

1898. Zur Methodik der hydrographischen Forschungen. Ann. d. Hydrog. u. maritimen Meteorol., Bd. XXVI, pp. 312-323.

Schott, G. 1902. Oceanographie und Maritime Meteorologie. Wiss. Ergebnisse der deulsch. Tiefsee-Expedition a. d. Dampfer Valdivia. Bd. I, 403 pp., 40 Taf.

Tanner, Z. L. 1897. Deep Sea Exploration: A General Description of the Steamer Albatross, her Appliances and Methods. Bull. U.S. Fish Comm., pp. 257-428, 40 Pls. and 76 text figures. 